\title{
THE EFFECTS OF BRANDS' POSTS ON SOCIAL MEDIA: CONCEPTUAL FRAMEWORK AND APPLICATION METHOD*
}

\author{
DOI: 10.17261/Pressacademia.2018.948 \\ JMML- V.5-ISS.3-2018(7)-p.238-250 \\ Abdullah Onden ${ }^{1}$, Meltem Kiygi-Calli2 \\ ${ }^{1}$ Fabrikod, 34664, Üsküdar, Istanbul, Turkey. \\ abdullah.onden@fabrikod.com, ORCID: 0000-0003-3769-8193 \\ ${ }^{2}$ Kadir Has University, 34083, Fatih, Istanbul, Turkey. \\ meltem.kiygicalli@khas.edu.tr, ORCID: 0000-0002-2979-9309
}

Date Received: July 11, 2018

Date Accepted: September 27, 2018

To cite this document

Onden, A., Kiygi-Calli, M. (2018). The effects of brands' posts on social media: conceptual framework and application method. Research Journal of Business and Management (RJBM), V.5(3), p.238-250.

Permemant link to this document: http://doi.org/10.17261/Pressacademia.2018.948

Copyright: Published by PressAcademia and limited licenced re-use rights only.

\begin{abstract}
Purpose- Many forms of brands' posts such as cointaining web links, images, photos and videos can be used for marketing research. The aim of this study is to present an approach to gather and analyze social media data and shows how marketers can derive useful outcomes from these data.

Methodology- The impacts of media types (link, text, video, photo), length, time (day-of-week and time-of-day) of brands' posts on customers' engagement are investigated. For this purpose, we propose a conceptual framework and mathematical model.

Findings- According to the conceptual framework and mathematical model given in this research, it is recommended to determine the effects of the content of the brands' posts on social media users.

Conclusion- Brands may determine the most effective content of the social media posts by applying the proposed mathematical model in this study.

Keywords: Digital marketing, social media, engagement, Twitter.

JEL Codes: M31, M39

\section{MARKALARIN SOSYAL MEDYADA YAPTIKLARI PAYLAŞIMLARIN ETKILERI: KAVRAMSAL ÇERÇEVE VE UYGULAMA YÖNTEMi*}

\section{ÖZET}

Amaç- Linkler, resimler, fotoğraflar and videolar gibi karakteristikleri bulunan çoğu çevrimiçi paylaşımlar pazarlama araştırması için kullanılabilir. Bu çalışmanın amacı markaların sosyal medya paylaşım verilerini toplamak ve analiz etmek için bir kavramsal çerçeve ve matematiksel model sunmak ve pazarlamacıların bu verilerden nasıl yararlı sonuçlar elde edebileceğini göstermektir.

Yöntem- Medya türlerinin (link, metin, video, fotoğraf) uzunluk, zaman (hafta içi gün ve gün) marka müşterinin etkileşimi üzerindeki etkileri incelenmiştir. Bu amaçla kavramsal bir çerçeve ve matematiksel bir model önerilmiştir.

Bulgular- Bu araştırmada sunulan kavramsal çerçeve ve matematiksel modele göre markaların yapmış olduğu paylaşımların içeriğinin sosyal medya kullanıcıları üzerindeki etkilerinin belirlenebilmesi önerilmektedir.

Sonuç- Markalar, bu çalışmada önerilen matematiksel modeli uygulayarak sosyal medya mesajlarının en etkili içeriğini belirleyebilirler.

Anahtar Kelimeler: Dijital pazarlama, sosyal medya, etkileşim, Twitter.

JEL Kodları: M31, M39

* This paper is based on the PhD. thesis entitled "Effects of Social Media Posts' Contents and Analysis of the Consumers' Responses to These Posts by Text Mining Method" which is written by Abdullah Önden under the supervision of Asst. Prof. Meltem Kiygi-Calli. Degree Granted: July 10, 2018 by Istanbul Okan University. 


\section{Gíriş}

Ülke sınırları aşılarak, insanların etkileşimde bulunduğu internet üzerinden içerik oluşturulmasını sağlayan sosyal medya kanalları, bilgiye anında ulaşılıp paylaşılmasına imkan vermektedir. New York merkezli veri ve dijital pazar araştırması şirketi eMarketer 2013 yılı ile birlikte Amerika Birleşik Devletleri'nde yaşayan yetişkinlerin yarısından fazlasının sadık bir sosyal medya kullanıcısı olacağını öngörmüştür (Grau, 2009). Yıl 2016 olduğunda bu rakamın \%78 değerine yükseldiği görülmüştür (Statistica, 2016). We Are Social'ın (2018) Global Dijital Rapor'una göre dünyada 4 milyar 21 milyon internet kullanıcısı bulunmaktadır. Bu sayı dünyadaki toplam 7 milyar 593 milyon kişinin \%53'üne denk gelmektedir. Bu kişilerin 3 milyar 196 milyonu aktif sosyal medya kullanıc olup, ayrıca mobil telefonlar üzerinden sosyal medyayı aktif olarak kullanan 2 milyar 958 milyon kullanıc bulunmaktadır. Aynı rapora göre internet kullanıcıları yıllık \%7 oranında büyürken, aktif sosyal medya kullanıcılarının sayısı \%13, mobil telefonlar üzerinden sosyal medyayı aktif olarak kullanan kişilerin sayısı yıllık \%14 oranında büyümektedir. Birçok işletme dijital platformlardaki bu potansiyeli fark edip dijital platformlara yatırım yapmakta ve dijital pazarlama stratejilerini oluşturmaktadır. Bu platformlar, kullanıcı sayılarının milyonlardan milyarlara ulaşması ile dünyadaki en değerli şirketler arasına girmiş durumdadırlar.

Sosyal medya insanların sadece deşarj olup servis sağlayıcıların ekonomik fayda kazandığı yerler değildir. Bu alanlar, dünya üzerinde milyarlarca insanın anlık düşüncelerini yansıttıkları, bir etki karşısında tepkilerini gösterdikleri alanlardır. Bu tepkiler sonucunda oluşan veriler; işletmeler, politika yapıcılar, araştırmacılar gibi bu bilgileri analiz edenler için değerlendirme ve yönlendirme imkanı sağlayan çok değerli kaynaklar oluşturmaktadır. Pazar analizi için gerekli örneklemin tespit edilip insanlar ile detaylı mülakat ve anketlerin gerçekleştirilmesi yerine, gönüllü olarak paylaşımda bulunmakta olan insanların gerçek tepkilerinden gerekli çıkarımın sağlanması mümkün olabilmektedir. Bu veri setinin doğru kullanılması ile popüler markaların oluşturulabilmesi, tercih edilen stratejilerin ve kampanyaların üretilmesi, anlık durumlar tespit edilerek markaya zarar verici tepkilerin önüne geçilebilmesi olasılıkları, insanların gönüllü olarak paylaşımlarına göre gerçekleştirilebilmektedir. Bu durum için, internetin pazarlama stratejilerinde açtığı farklı bir sayfa denilebilir. Fakat sosyal medyanın pazarlama alanında sunmakta olduğu avantajlardan faydalanılabilmesi için sadece pazarlama alanının kabiliyetleri yeterli olamayacaktır. Kavramsal çerçevesi pazarlama literatürü kapsamında geliştirilmiş olan çalışmalara ek olarak, veri biliminin de araştırmalarla bütünleştirilme gerekliliği bulunmaktadır. Bu durum, büyük veri kavramını da işin içerisine almaktadır. Büyük veri niteliği yapısı itibari ile karmaşık ve dağınık veriyi anlamaya, standart dışı olan verinin elenip temizlenmesine, istatistiki dağılımlara uygunluğuna yönelik algoritmalar araştırılıp geliştirilmesini sağlayacaktır. Dolayısı ile heyecan verici bu yeni alan disiplinler arası bir nitelik kazanmaktadır. Pazarlama çatı olmak kaydı ile, bununla birlikte bilgisayar bilimi, veri madenciliği ve istatistik de yer almaktadır.

İnsanların paylaşım ve tepkilerinin oluşturduğu bu veri setinin analiz edilmesi sonucunda ürün, bölge, cinsiyet veya strateji odaklı başarı hedeflerinin tespit edilebilmesi mümkün olabilecektir (Kim vd., 2014). Bu yeni yapı tamamen insanların kendi arzularıyla gerçekleştirdikleri paylaşımlar ve bir karşılık beklemeden vermekte oldukları tepkilerin doğru analizi sonucunda gerçekleşecektir. Bu durum sonucunda geçmiş zamanlarda toplanan veriler ve sonuçları sayesinde, gelecekte çıkacak bir ürün için geliştirmeler yapılabilecekken, daha ürün piyasaya girmeden alacağı tepkiler tahmin edilebilecektir. Sosyal medya ve metin madenciliğinin değeri bu noktada ortaya çıkmaktadır. Geleneksel pazarlama stratejilerinde, reklam yatırımları satışlar ile de ölçülebilirken, piyasaya çıkması düşünülen bir ürüne yönelik algının olumlu ya da olumsuz olduğunun ölçülebilmesi mümkün olabilmektedir. Bu noktada genel olarak bir örneklemle çalışma zorunluluğuna karşın, internetin sunmakta olduğu yeni mecralarda, belirli bir örneklem ile çalışılabileceği gibi, teknik altyapının sağlanması durumunda ürün ile ilgili dünyadaki tüm kullanıcıların ana kütlesi üzerinde çalışmak mümkün olabilecektir. Bu durum hem kurumsal, hem de akademik merakın cezbedilebilmesi için yeterli motivasyonu sağlamaktadır. İşletmelerin mevcut müşterilerinin yanında yeni müşteriler kazanması da çok önemlidir. Bu sebeple işletmelerin markalama stratejilerinde, özellikle yeni bir ürün lansmanlarında, mevcut müşterilerin yanında potansiyel müşterilerin de ürüne karşı olan tutumlarının ne olduğu ve nasıl değiştiği pazarlama stratejilerinin oluşturulasında çok etkin bir faktördür. Sosyal medyadan elde edilen verilerle, hem daha önce pazara sunulmuş ürünlerin pazarda başarılarının devam etmesi, hem de yeni pazara sunulan ürünlerin pazarda başarıya ulaşması için gerekli doneler elde edilebilir ve işletmenin gelecekle ilgili daha doğru staratejiler oluşturulması sağlanabilir.

Bu çalışmada, işletmelerin sosyal medya üzerinden yaptıkları paylaşımların tüketiciler üzerindeki etkileri incelenerek işletmelerin pazarlama stratejilerinin yeniden yapılandırılmasına yardımcı olmak temel amaçtır. Araştırmada pazarlamanın önemli unsurlarından tutundurma stratejilerinin bir uygulaması olan sosyal medya pazarlaması ele alınmıştır. İşletmelerin kendi resmi sosyal medya hesapları üzerinden yaptıkları paylaşımlara sosyal medya kullanıcılarının vermiş oldukları geri bildirimler incelenmiştir. Bu geri bildirimler tüketicilerin işletmenin resmi sosyal medya hesaplarından yaptıkları paylaşımları beğenmeleri, cevap vermeleri ve paylaşmalarıdır. İşletme paylaşımlarının tüketiciler üzerindeki etkisinin araştırılması için kavramsal bir çerçeve ve model oluşturulmuştur. 


\section{LITERATÜR INCELEMESI}

\subsection{Sosyal Medya ve Fonksiyonları}

Literatürde sosyal medya farklı şekilde tanımlanmaktadır. Bunlardan örnek vermek gerekirse; Kaplan ve Haenlein (2010)'a göre sosyal medya internetin köklerine geri dönüşüdür, yani kullanıcıların birbirleri ile bilgi alışverişi yapabildiği bir platformdur. Sosyal medya, web 2.0'ın getirdiği ideolojik ve teknolojik yapı üzerine kullanıcılar tarafından özgürce içerik oluşturulmasına izin veren internet tabanlı uygulamalardır (Kaplan ve Haenlein, 2010). Safko (2010) ise sosyal medyayı, insanların internet üzerinden sosyalleşmek için kullandıkları medya türü olarak tanımlamıştır. Eley ve Tilley (2009) sosyal medyayı, blog ve forum gibi platformlarda; yazı, fotoğraf, video gibi içerikler barındıran, kullanıcıların kendilerine ait hesap ve sayfalarının olduğu ve buna benzer sosyal ağları içeren geniş bir yapı olarak nitelendirmişlerdir (Eley ve Tilley, 2009). Blossom (2009)'a göre ise sosyal medya; her bireyin diğer birey gruplarını kolaylıkla etkilemesine imkan veren, yüksek derecede ölçeklenebilir ve erişilebilir iletişim teknolojileri ya da teknikleri olarak tanımlanmaktadır. Webber (2010)'a göre bugünlerde atılan basit ama zekice bir tweet, yaratıc bir şekilde oluşturulmuş bir blog yazısı ya da insanı şoka eden bir video yüzlerce insanın paylaşımı ile bir ürünü yok edebilir ya da markanın pazar payına zarar verebilir.

Tüketici tarafından üretilen içerik (consumer generated content - CGC) olarak da kabul edilen kullanıcı tabanlı içerik (user generated content - UGC), sosyal medya kullanıcıları tarafından oluşturulan yazılı, görsel ya da işitsel kavramlar olarak ortaya çıkmıştır. Günümüz teknolojisini avantaja çevirmek için pek çok işletme artık müşterileri içerik üretmeye teşvik etmektedir (Kotler ve Armstrong, 2012). Kullanıcı tarafından oluşturulan içerikler insanların sosyal medyadan faydalanırken ürettikleri yazı, görsel, video vb. içeriklerdir. Sosyal medyadaki medya platformları yapılarına göre kendi aralarında belirli sınıflara ayrılabilirler. Burada trafik, kalite, ülke, mobil ya da masaüstü hedeflemeleri gibi teknik ve sosyal pek çok tanımlama kullanılabilir.

Kietzmann ve diğerleri (2011) sosyal medyayı "kimlik, diyalog, paylaşım, görünürlük, ilişkiler, itibar, gruplaşma" kavramlarına göre yediye bölmüş ve buna bal peteği çerçevesi ismini vermiştir. Bu yedi bloğun çoğu sosyal medyadaki tüm bilinen platformlarda bulunur. Bu yedi maddenin sosyal medya platformundaki yoğunluğu veya az olması, platformun karakterini belirler. Örneğin Facebook'ta kimlikler, gruplaşma ve ilişkiler ön plandayken, Youtube'da paylaşım, Foursquare ve Swarm'da görünürlük öne çıkmaktadır. Şekil 1'de gösterilen sosyal medyanın yedi fonksiyonu şu şekilde açıklanabilir:

1.Kimlik: Internet kullanıcıları gerçek hayatta bir fiziksel kimliğe sahiptiler. Sosyal medyada ise bu kimlik kimi sitelerde tamamen gizlenip anonim kalırken, kimisinde açık şekilde sunulmaktadır. Her ikisinde de gerçek ya da sanal da olsa bir kimlik vardır (Kaplan ve Haenlein, 2010).

2.Diyalog: Sosyal medyanın getirdiği temel özelliklerden birisi diyalog kurma yani karşılıklı fikir alışverişidir. Bu fonksiyona temelden bağlı en büyük sosyal medya platform örnekleri olarak Twitter ve Reddit gösterilebilir (Kaplan ve Haenlein, 2010).

3.Paylaşım: Sosyal medyanın temel çıkış sebeplerinden biri de insanların internet üzerinden birbirleri ile paylaşım yapabilmeye ihtiyaç duymasıdır. Buna yönelik olarak kurulan Stumble Upon ve Digg gibi siteler, internette arka planda kalan içeriklerin ön plana çıkarılmasını sağlıyordu. Geri planda kalan bu sosyal imleme sitelerine nazaran Facebook internete getirdiği devrim ile kişilerin kendi arkadaşlık ağını kurmasına dayanıyordu. Facebook'un temel yapısal blokları olan etkinlikler, sayfalar, gruplar, uygulamalar, kişilerin özel duvarları ve diğer modülleri ile sosyal medyada çok daha hızlı ve etkili şekilde paylaşım yapılabilmesini sağlamaktadır (Engeström, 2005).

4.Görünürlük: Internet ilk kullanılmaya başlandığından beri, sabit giderler karşılandığı zaman bilgi edinimini ücretsiz ve detaylı bir şekilde insanlara sağlamayı amaçlamıştır. Sosyal medya platformları da bir araya getirdikleri kullanıcılara yazı, yorum, görsel ve benzeri içerikleri oluşturup dünyaya özgürce duyurma imkanı sağlamaktadır. Burada içeriğin diğer kişiler tarafından paylaşılıp yayılabilmesi için görünür olması gerekmektedir. Platformlar kullanıcıları istemediği takdirde ve bir hukuki ihlal yapılmaz ise görünürlüğünü engellemez (Kietzmann vd., 2011; Kaplan ve Haenlein, 2010).

5.ilişkiler: Web 1.0 ile sosyal medyayı en fazla ayıran temel farklardan biri de ilişki faktörüdür. 1998 yılında bir internet kafede Yahoo arama motoru ile internette ödevine kaynak arayan bir kişi, istediğini bulamadığında kalkıp giderken, Web 2.0'ın getirdiği teknoloji ile forumlarda ya da ilgili sitelerde aradığı detayları vererek ilan açıp duyuru yapabiliyor ve karşılıklı konuşabiliyor. Sosyal medya ile kullanıcılar artık kendi arkadaş grubunu çevrimiçi olarak takip edebildiği gibi, yeni arkadaşlıklar kurabileceği platformlara da sahip oldu. Literatürde "Sosyal medya" ismi ile kabul ettiğimiz bu yapının "sosyal" kelimesinin çoğunu ilişki kavramı oluşturmaktadır ve bir dijital araçtan ziyade gerçek dünyaya etkisi olan güçlü bir yapıdır (Borgatti ve Foster, 2003; Kaplan ve Haenlein, 2010).

6.ittibar: Sosyal medyanın temel yapı taşlarından kendini-ifşa ve kendini-tanıtma özellikleri ile birlikte kullanıcılar internette de bir kimliğe sahip olmaya başlamıştır. Bunu yaparken bir kullanıcı adı arkasına saklanabilecekleri gibi hiçbir gizlenme olmadan 
kendi isimleri ile de paylaşım yapabilirler. İtibar kavramının en öne çıktığı örnek Linkedin ve Twittter olarak verilebilir (Kietzmann vd., 2011).

7.Gruplar: Cengiz Han'ın "bir ok kolayca kırılabilir, fakat bu oklar bir arada kırılmaz olurlar" mantığı ile internette de bir araya gelen kullanıılar hem içerik üretimi hem birlikte hareket noktasında daha yaratıcı ve üretken olurlar (Dunbar, 1992; Kietzmann vd., 2011).

\section{Şekil 1: Sosyal Medyanın Yedi Bloğu}

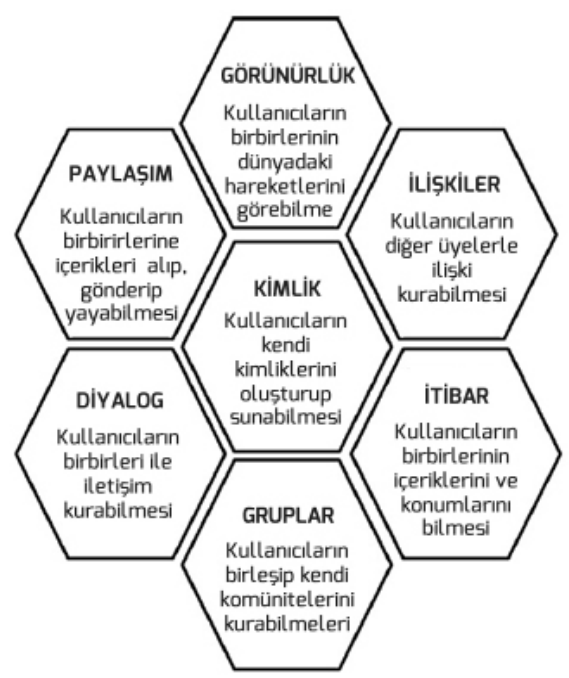

Sosyal Medya Fonksiyonları

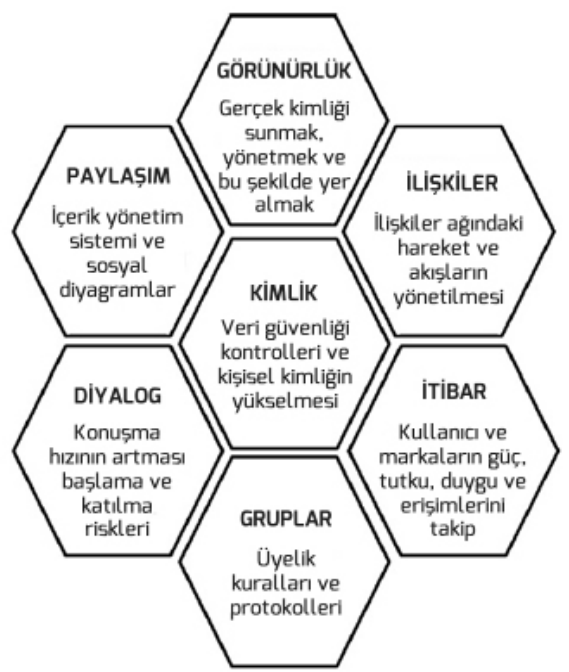

Fonksiyonların Etkileri

Kaynak: Kietzmann, JH., Hermkens K., McCarthy I.P, ve Silvestre B.S. (2011). Social media? Get serious! Understanding the functional building blocks of social media. Business Horizons, 54(3), 241-250.

\subsection{Dijital Pazarlama}

Dijital pazarlama internet, mobil telefon, görüntülü reklam gibi dijital teknolojilerin kullanılarak ürün veya hizmetlerin pazarlamasıdır (Ryan ve Jones, 2009). Özellikle 2000'lerden sonra, dijital pazarlamada farklı teknolojilerin kullanılması ile birlikte bu uygulamalar tüketicilerin günlük yaşantısına daha çok nüfuz etmiş ve fiziksel olarak bir mağazaya gitmek yerine dijital platformlar üzerinden alışveriş yapmak tüketiciler için daha verimli olmaktadır (Nielsen, 2016). Web tabanlı platformların hızlı büyümesi, insan faaliyetleri ve etkileşimlerinin doğasını önemli ölçüde değiştirmiştir. Gerçek dünyadaki sosyal ilişkiler, sanal dünyaya aktarılmış, bu da insanları dünya çapında bir araya getiren çevrimiçi toplulukların oluşmasına yol açmıştır. Dijital boyuttaki bu hareket, bireylerin bilgiyi paylaşmasına, birbirini eğlendirmesine ve farklı kültürler arasında diyaloğu teşvik etmesine izin verir (Budden vd., 2011; Kumar vd., 2010). Birçok işletme interaktif tüketici pazarındaki bu potansiyeli fark edip özellikle genç, iyi eğitimli, geliri orta sınıfın biraz üzerinde olan tüketici grubunu hedef alacak şekilde özel pazarlama stratejileri geliştirmektedir (Kierzkowski vd., 1996). Bu nedenle işletmeler özellikle dijital teknoloji kullanıcılarını hedef alan pazarlama kampanyaları üretirken bu konularda araştırma yapma gerekliliği de ortaya çıkmıştır. Dijital pazarlamadaki uygulamaların artması ile birlikte özellikle işletmelerin ilişki tabanlı araştırmalara daha çok kaynak ayırması ve çaba sarf etmesi gerekmektedir (Tiago vd., 2014). Tüketici bakış açısı ile konu ele alındığında ise özellikle bu tür teknolojilerin pazarlamada kullanılmasının tüketicilere çok sayıda fayda sağladığı görülmektedir. Bu faydalar kolaylık, zengin ve paylaşımcı bilgi, daha çok ürün seçeneği, rekabetçi fiyat, maliyet azalması olarak sıralanabilir (Bayo-Moriones ve Lera-Lopez, 2007).

Çevrimiçi sosyal ağlar, tüketiciler ile daha proaktif bir şekilde iletişim kurdurabildiği için, tüketicilere sağlanan faydaları artırmaktadır. Örneğin, çevrimiçi sosyal ağlar aracılı̆̆ıyla, bireyler belirli ürünler hakkında diğer kullanıcıların görüşlerini alabilirler. Tüketicilerin çoğu sosyal medya üzerinden etkileşimde bulundukları için, işletmeler de sosyal medya üzerinden tüketicilerle etkileşimde bulunmaktadırlar (Berthon vd., 2012). Geçmiş ve günümüz arasındaki kritik fark ise çevrimiçi iletişim araçlarının müşterilerin işletmelere yanıt verebilmelerine izin vermesidir (Mangold ve Faulds, 2009). Müşterileriyle iletişim kurmak isteyen işletmeler için özellikle önemli olan, internet üzerinden katılımcı bilgi paylaşımının ortaya çıkmasıdır. Bu durum, iletişim teknolojisindeki global gelişmeler ve internet erişimi için daha düşük maliyetler ile birleştiğinde, özellikle tutundurma karması boyutuna bağlı olarak dijital pazarlama stratejilerinde büyük değişimlere sebep olmaktadır. Bu stratejiler sadece daha etkili pazarlama stratejileri değil, aynı zamanda yeni bir ilişki paradigmasına da izin vermektedir (Silva vd., 2008). Bunlar 
işletmeleri daha dijital ortamda bulunmaya zorlamaktadır. İşletmeler bir sosyal devrim olan Web 2.0 teknolojilerine uyum sağlamışlardır.

Pazarlama literatüründe markaların oluşturmuş olduğu tutundurma stratejilerinin tüketiciler üzerindeki etkileri niteliksel ve niceliksel olarak çok uzun yıllardır araştırılmaktadır (Little, 1979; Kiygi-Calli vd., 2012). Son yıllarda tutundurma stratejilerinden olan sosyal medya pazarlamasının etkilerinin ölçülmesi konusunda çok fazla araştırma yapılmaya başlanmıştır (Smith vd., 2012; Nam vd., 2017; Truong vd., 2017). Yöneticiler, müşteriler ile ilişkileri güçlendirmek ve etkileşimde bulunmak için sosyal medyaya yatırım yaparlar (Gillin, 2010). Bu amacı gerçekleştirmenin bir yolu sosyal medyada kendi marka sayfalarını oluşturarak müşterilerin işletme ile etkileşimde bulunabileceği marka toplulukları yaratmaktır (McAlexander vd., 2002; Muñiz ve O'Guinn, 2001). Bu marka sayfalarının takipçisi olan tüketiciler, işletmeye sadık ve bağlı olma eğilimindedir ve marka hakkında bilgi almaya daha açıktır (Bagozzi ve Dholakia 2006). Dahası, marka tutkunları mağazayı daha fazla ziyaret etme, daha olumlu yorum yapma ve markayla daha duygusal olarak bağ kurma eğilimindedirler (Dholakia ve Durham, 2010). Marka sadakati, belirli bir marka için tüketicinin tercihi ve bu markayı tekrar tekrar satın alma taahhüdüdür (Dick ve Basu, 1994). Sadakat programları, tüketici tercihlerini ve alışkanlık alışkanlıklarını takip edebilmek için müşterileri tekrarlamak için ödüller sunar. Pazarlamada marka sadakati, bir tüketicinin markayı geri satın alma veya kullanmaya devam etme taahhüdünden oluşur (Sharp ve Sharp, 1997). Üçüncü taraf onayları gibi tekniklerin kullanılması ve yerleşik itibara sahip şirketlerle stratejik ortaklıklar güven düzeyini arttırmaktadır. Ürünün genel performansı müşteri beklentilerini karşılaması veya aşması davranışsal sadakati kolaylaştırmaktır. Özel ürünler sunarak, marka değiştirme için teşvikler sağlamanın yanı sıra, frekans programlarını kullanmak, bunu başarmanın yöntemleridir (Gommans vd., 2001).

Pazarlama faaliyetlerinin sosyal medyadaki başarısı üzerine araştırmalar yapılırken, marka popülerliğini etkileyen faktörler olarak, marka hayran sayfası ve paylaşımlarının beğeni ve yorumlarının sayısı olduğu bilinmektedir. (Ryan ve Zabin, 2010; Shankar ve Batra, 2009). Marka popülerliği ile ilgili yönetim odaklı çalışmalar temel olarak tanımlayıcıdır; teorik bir temel oluşturmazlar ve hangi tip çalışmaların marka popülerliğini artırdığını net bir şekilde ifade edemezler. Örneğin, işletmelerin sosyal medyadaki paylaşımlarının tiplerinin video, resim, metin veya soru gibi farklı özelliklerde olmasının getirilerini denemeler yaparak öğrenilmesini önermektedir (Brookes, 2010; Keath vd., 2011). İşletmelerin yaptığı paylaşımlar marka kimliği ile uygun olmalıdır, çünkü kimlik markanın dışa dönük ifadesidir. Böylece marka sahibi tüketicinin markayı nasıl algılayacağını ve müşterinin zihninde nasıl yer alacağını marka kimliği ile oluşturur. Bu nedenle işletmelerin sosyal medya üzerinden yapacakları paylaşımlarda marka kimliğine uygun olarak paylaşım içeriğini oluşturmaları gerekmtekedir. Ayrıca tasarım öğelerinin renk, şekil, malzeme, yazı biçimi ve kompozisyon gibi benzersiz alfabesi olan görsel marka dilini de sosyal medya üzerinden doğru bir şekilde oluşturması gerekmektedir (Brunner vd., 2008). Çünkü görsel marka dili de işletmenin değerlerini ve kişiliğini, etkileyici imgeleme ve tasarım stili aracılığıyla doğrudan ve bilinçaltı olarak tüketiciye etki eder (Lockwood ve Walton, 2008). Sosyal paylaşım siteleri özellikle son yıllarda çok popüler hale geldi. Sosyal paylaşım siteleri sosyal veya profesyonel etkileşimler için arkadaş ağları olarak tanımlanabilir (Trusov vd., 2009). Sosyal paylaşım sitelerinin üyeleri diğer üyelerle arkadaş olabilirler, ancak marka hayran sayfalarında markanın takipçisi olabilirler. Marka taraftarları markayla ilgili heyecanlarını bu özel sayfalarda paylaşabilir ve markanın ortak çıkarları için birleşebilirler (Kozinets, 1999).

Marka hayran sayfaları, müşterilerin marka ile olan ilişkisini (McAlexander vd., 2002) yansıtır, marka-müşteri ilişkisini (Muñiz ve O'Guinn, 2001) genişletir ve üyelere bir bilgi kaynağı ve sosyal fayda sağlar. (Bagozzi ve Dholakia, 2006; Dholakia vd., 2004). Bu hayran sayfalarında tüketiciler, işletme ile ilgili anekdotlar, fotoğraflar, videolar veya diğer materyalleri içeren marka gönderileri oluşturabilir; marka hayranları daha sonra bu marka yayınlarıyla etkileşime girerek veya yorum yaparak etkileşimde bulunabilirler. Marka veya hayranlarının paylaşımları sonrası "popülerlik" beğenilerin ve yorumların sayısı olarak ölçümlenebilir. Paylaşım sonrası popülerliği paylaşım karakteristiklerini etkileyebilir (De Vries vd., 2012). De Vries vd. (2012) markanın sosyal medya paylaşım popülerliğini artıran faktörleri ampirik olarak araştırmışlardır. Banner ve reklam literatüründen elde edilen bulgulara ve ağızdan ağıza iletişim literatürüne dayanan kavramsal bir model geliştirmişlerdir. Marka paylaşım özelliklerini (örneğin canlılık, etkileşim), paylaşım içeriğinin (ör: bilgi, eğlence), marka paylaşım konumlandırması ve marka taraftarları tarafından yazılan marka hakkında yorumların değerlerini dikkate almıştır. Marka gönderisindeki beğeni ve yorumlar, marka hayranlarının aktif ifadelerini yansıtır ve başkaları tarafından görülebilir. Markaları beğenerek veya yorumlayarak, marka hayranları düşüncelerini kamuya açıklar, bu da ağızdan ağıza iletişime benzemektedir (De Vries vd., 2012).

Sosyal medya müşterilerin marka memnuniyeti, imajı ve bilinirliğini konuştuğu böylece işletmelerin markalarını doğrudan etkileyen bir platform olarak gelişmektedir. Bu da işletmelerin markalarını duyurabilmesi için yeni fırsatlar doğurmakta ve özellikle perakende sektöründeki fiziksel mağazalar için yeni bir satış kanalı oluşturulmasını sağlamıştır (Ibrahim vd., 2017). Bir markanın sosyal medya paylaşımlarından etkilenmesinin en temel sebebi, kendilerinden bahseden kullanıcıların içeriklere duygularını katmalarıdır. Sosyal medyada yer alan duygular, müşteri ve işletmeler olaya dahil olduğunda marka için bir problem yaratabilir (Barnaghi vd., 2016). Her gün milyonlarca içeriğin paylaşıldığı sosyal medyada bu içeriklerin duygu analizi ve eWOM'un ölçülebilmesi için araçlar geliştirilmeye başlanmıştır (Huberman vd., 2008). Paylaşımlardaki duygusal değişimler, bu 
değişimlerin sebep olduğu dönüşümler, sosyal medya etkileşiminin sebep olduğu ortalama duygu geçişleri araştırılmaya devam edilmektedir (Kim vd., 2014; Roshanaei ve Mishra, 2015). Sosyal medya üzerindeki ağızdan ağıza pazarlama üzerine yapılan çalışmalarda, bu paylaşımların işletmelerin satış rakamlarını etkilediği görülmüştür (Zhou ve Duan, 2015). Sosyal medya istatistiklerinin takip edilmesi de işletmelerin genel durumlarını görmeleri için imkanlar sunmaktadır. Hem pazar hem de rakiplerin genel durumu ve rekabet ile ilgili bilgi veren sosyal medya üzerinden işletmeler markalarının güçlü ve zayıf yönlerini analiz ederek ürün ve organizasyonlarını daha efektif bir hale getirebilmektedirler (He vd., 2013). Tüm bu çalışmalar işletmelerin sosyal medyadaki durumlarını anlık olarak takip ederek daha karlı bir yapıya sahip olabileceklerini gösterirken, bunun için gerekli ekip ve teknolojik altyapının kurgulanması ve pazarlama tarafında da paylaşılan bu milyonlarca içeriğin doğru analiz edilebilmesi için gerekli araştırma ve geliştirmenin yapılması gerektiği sonucuna ulaşılmasını sağlamaktadır.

Word-of-mouth (WOM) yani ağızdan ağıza pazarlama son zamanlarda uygulayıcılar tarafından büyük ilgi gördü. Örneğin, birkaç kitap geleneksel pazarlama iletişim araçlarına uygun bir alternatif olarak WOM'u sundu (Misner ve Devine, 1999). Pazarlamacılar özellikle WOM'un daha iyi anlaşılmasıyla ilgileniyorlar çünkü geleneksel iletişim biçimleri etkinliğini kaybetmektedir (Nail, 2005). Moralıoğlu (2014)'a göre “Fısıltı pazarlaması, en temel ifade ile tüketicilerin diğer tüketiciler ile ürünler, hizmetler, kısaca markalar hakkında bilgi paylaşmasıdır. Bir tüketiciden diğerine marka bilgisinin aktarımıdır. Fısıltı pazarlaması, ağızdan ağıza pazarlamayla ürünlerin ve markaların geliştiği, ifade edildiği ve yayılarak informal bir iletişimin sağlandığı bir yöntem olarak da tanımlanabilir".

Ağızdan ağıza iletişim stratejileri özellikle internet teknolojisini kullanarak tüketici direncinin çok daha düşük maliyetlerle ve daha hızlı bir şekilde kırılmasını sağlamaktadır. Ağızdan ağıza pazarlama günümüzde internet üzerinde giderek kuvvetlenen bir yapıdadır. İnternet, tüketicilerin görüşlerini, tercihlerini ya da deneyimlerini başkalarıyla paylaşmalarının yanı sıra işletmelerin WOM pazarlamasından faydalanma fırsatları için çok sayıda ortam sunmaktadır (Trusov vd., 2009). Elektronik ağızdan ağıza pazarlama (eWOM), tüketiciler tarafından üretilen ve sosyal medya, web siteleri, inceleme platformları veya internet forumları gibi web tabanlı hizmetler aracılığıyla kamuya açık bir ürün, hizmet veya işletme hakkında her türlü olumlu veya olumsuz beyan olarak tanımlanmaktadır (Hennig-Thurau vd., 2004). Olumlu eWOM, satışları önemli ölçüde artırmaktadır (Chevalier ve Mayzlin, 2006; Pauwels vd., 2016). Bunun aksine olumsuz eWOM da, daha düşük ürün imajına (Ho-Dac vd., 2013), işletme değerine (Goldenberg vd. 2007) ve satışlara (Dellarocas ve Wood, 2008) yol açmaktadır. Az bilinen markalar, farkındalığın artmasıyla olumsuz eWOM'dan yararlanabilirler (Berger vd., 2010). Rakiplerinin zayıflayan imajlarını doğru strateji ile avantaja çevirebilirler. Öte yandan, bir markayla güçlü bir şekilde özdeşleşen tüketiciler, olumsuz eWOM'a çok az tepki göstermekte ya da hiç tepki göstermemektedir (Ho-Dac vd., 2013; Wilson vd., 2017). Yeni ürün tanıtımları (Marchand vd., 2017), etkinlikler (Trusov vd., 2009) ve reklam kampanyaları (Pauwels vd., 2016) gibi belirli marka etkinlikleri eWOM'ları tetikleyebilir.

eWOM üzerine yukarıda açıklanan araştırmalar göstermektedir ki web tabanlı sistemlerde, özellikle müşteri inceleme siteleri ve çevrimiçi forumlardaki paylaşımlar büyük ölçüde tüketicileri etkilemektedir. Sosyal medya siteleri, kullanıcılara doğrudan paylaşım imkanı vererek insanların düşüncelerinde dinamik değişimlere de sebep olabilmektedir. Olumlu ya da olumsuz eWOM, tüketicileri sadece satın almaktan vazgeçirmek ya da motive etmekle kalmayıp, aynı zamanda, söz konusu iki taraftan birini desteklemek isteyenlerin, diğer tüketicilerden daha fazla eWOM ve sosyal medya faaliyetlerini yapmasını da tetikleyebilir. eWOM, ürün ya da hizmetten memnun olan ya da memnun olmayan tüketiciler ile şirketler arasında ikili bir etkileşim kurmasını sağlar. Böylelikle sosyal medyada içerik yayını yapan müşteri, şirket ve müşteriden etkilenebilecek potansiyel müşterileri kapsayan üçgen bir yapıya oluşmuş olur (Kozinets vd., 2010).

\section{VERI VE METODOLOJi}

Zengin araştırma kaynakları ve internetin mükemmel erişilebilirliği sayesinde sosyal medyada yayınlanan içerikleri metin madenciliği ile işleyip, paylaşımın duygu analizini yapmak ve sayesinde tüm dünyadan insanların istek, arzu ve davranışlarının daha iyi anlaşılmasına olanak sağlamaktadır. Sosyal medyadaki büyük verinin analiz edilmesi için özellikle veri madenciliği metodu kullanılmaktadır. Veri madenciliği en kısa tanımı ile büyük ölçekli bir veri grubu arasından anlamı olan bilgiyi elde etme çalışmasıdır (Özkan, 2008). Frawley vd. (1992) veri madenciliğini şöyle tanımlamıştır: "Veride saklı halde bulunan ve geçmişte bilinmeyen ancak faydalı olacağını düşündüğümüz bilginin açığa çıkarılmasıdır".

Diğer bir ifade ile veri madenciliği; veri tabanlarında depolanmış verilerden yeni, yararlı ve anlamlı bilgilerin edinilmesi işlemidir. Veri Madenciliği yöntemleri temel aldıkları teknik ve disiplinlere göre aşağıdaki gibi gruplanabilir (Alpaydın, 2000):

- Sınıflandırma (Classification): Hangi sınıfa ait olduğu bilinmeyen kayıtların sınıf belirleme sürecine sınıflandırma ismi verilir. Verileri sınıflandırmada yaygın olarak "karar ağaçları" yöntemi kullanılır.

- $\quad$ Kümeleme (Clustering): Dağınık yapıdaki bir veri setini tanımlayıp düzene sokmak için belirli sayıda kümeye bölüp sıralama işlemine "kümeleme" adı verilir. Birbiri ile benzer yapıdaki verileri ayırma işlemi olan kümeleme yönteminde veriler arasındaki uzaklık kullanılır. 
- Birliktelik Kuralları (Associaton rules): Büyük ve dağınık veri kümeleri arasındaki yapısal ve içerik ilişkilerini bulan, olayların birlikte gerçekleşme ihtimallerini eski verileri analiz edip ortaya koyarak geleceğe yönelik çalışmalar sunan veri madenciliği yöntemine "birliktelik kuralları" denmektedir. Birliktelik kurallarında, verinin diğer veriler ile yakınlığı göz önüne alınarak birlikte olma durumu üzerine olasılık işlemleri yapılır. Müşteri bir ürün aldığı zaman bu ürünle birlikte başka hangi ürünleri aldığının tespitinin yapılması için bu teknikten yararlanılır (Akçay, 2013).

\subsection{Kavramsal Çerçeve ve Matematiksel Model}

Bu çalışmada işletmelerin kendi marka hesapları üzerinden sosyal medyada yaptıkları paylaşımlara sosyal medya kullanıcılarının (tüketici) nasıl bir geri bildirimde bulundukları kavramsal çerçeve olarak oluşturulmuştur. Bu geri bildirimler tüketicilerin marka resmi sosyal medya hesaplarından yaptıkları paylaşımları beğenmeleri, cevap vermeleri ve yeniden paylaşmalarıdır. Bu çalışmanın amacı özellikle markaların yapmış oldukları paylaşımların karakteristik özelliklerinin değişiminin kullanıcı geri bildirimleri üzerinde farklı etkilerinin olup olmadığının bir model önerilmek koşuluyla araştırılmasıdır. Paylaşımların karakteristik özellikleri aşağıda içerik tipi, uzunluk ve işletmenin paylaşımı yaptığı gün ve saat olarak bu çerçevede belirlenmiştir. Aşağıda bu karakteristikler açıklanmaktadır.

İçerik Tipi: Paylaşımın yapı olarak içeriğini belirtir. İçerik tipleri metin, resim, video, gif veya link olabilmektedir. Her bir içerik tipi için kukla değişken oluşturulabilir.

Uzunluk: Paylaşımın toplam karakter uzunluğu ve bu uzunlukların çok kısa (0 ile 50 karakter arası), kısa (51 ile 100 karakter arası), orta (101 ile 150 karakter arası) uzun (151 ile 200 karakter arası), çok uzun (201 ve üzeri) şeklinde olarak gruplanabilir. Her bir grup için farklı kukla değişkenler oluşturulabilir.

Saat Aralığı: Paylaşımın günün hangi saatinde atıldığı bilgisini içerir. Günün 24 farklı saat aralığı için 24 farklı kukla değişken oluşturulabilir.

Haftanın Günü: Paylaşımın haftanın hangi gününde atıldığı bilgisini içerir. Haftanın 7 farklı günü için 7 farklı kukla değişken oluşturulabilir.

Sosyal medya üzerinde yapılan paylaşımların içeriğinin sosyal medya kullanıcıları üzerindeki etkileri kullanıcıların yapmış oldukları beğeni, paylaşım ve yorum-cevap sayısı olarak ölçümlenebilir. Beğeni, paylaşım ve yorum sayılarının içeriği aşağıda açıklanmıştır.

Beğeni: Sosyal medyanın ilk ve en temel özelliğidir. Bu özellikle üye bir gönderiyi beğendiğinde kendisini takip eden kullanıcılara sitenin bir bölümünden bilgi verilerek kendilerinin de ilgili gönderiye ulaşmaları sağlanır, böylelikle ağızdan ağıza pazarlama tamamen organik şekilde yolculuğuna başlamış olur. Beğenme özelliği Facebook, Instagram ve Twitter'da mevcuttur.

Paylaşım: Bir gönderinin kişinin özel profilinde resmi, linki ve diğer açıklamaları ile yer almasıdır. Bu özellik Facebook'ta bulunurken, Twitter'daki hali Retweet'tir. Instagram'ın böyle bir özelliği olmasa da üçüncü parti uygulamalarda bunu kullananlar mevcuttur.

Yorum - Cevap: Yorum internetin Web 1.0 halinden beri sık şekilde kullanılan bir teknolojidir. Bilhassa haber sitelerinin çoğu internet kullanıcılarının yorum kültürünün gelişmesini sağlamıştır. Sosyal medya ile birlikte de tüm gönderilere yorum yapılabilmesi şansı verilmiştir. Yorumlar tüm paylaşım araçları içerisinde en değerli bilgileri içerirler fakat büyük kampanyalarda tüm yorumların okunabilmesi mümkün olmadığı için bir yere kadar değerlendirilebilirler. Yorum özelliği Facebook ve Instagram'da mevcutken, Twitter'da ilgili bir tweete yanıt yine bir tweet ile verilmektedir.

\section{Çalışmanın Araştırma Sorusu}

Markaların yapmış oldukları paylaşımların karakteristik özelliklerinin değişimi (paylaşım içeriğinde metin, resim, video, link, gif bulunup bulunmaması, metin uzunluğu, paylaşımın yapıılığı gün ve saat) kullanıcı geri bildirimlerini (toplam beğeni, paylaşım, yorum) nasıl etkilemektedir?

\section{Çalışmanın Hipotezleri}

H1: Markaların yapmış oldukları paylaşımlarının içeriğinde video bulunmasının, kullanıcıların paylaşıma yaptıkları toplam beğeni sayısı üzerinde, paylaşımın içeriğinde sadece metin bulunmasına göre daha pozitif anlamlı bir etkisi yoktur/vardır.

H2: Markaların yapmış oldukları paylaşımlarının içeriğinde resim bulunmasının, kullanıcıların paylaşıma yaptıkları toplam beğeni sayısı üzerinde, paylaşımın içeriğinde sadece metin bulunmasına göre daha pozitif anlamlı bir etkisi yoktur/vardır.

H3: Markaların yapmış oldukları paylaşımların karakter sayısının artmasının kullanıcıların paylaşıma yaptıkları toplam beğeni sayısı üzerinde, paylaşımın içeriğinin daha kısa olmasına göre daha pozitif anlamlı bir etkisi yoktur/vardır. 
H4: Markaların paylaşımlarının haftanın hangi gününde yapıldığının kullanıcıların paylaşıma yaptıkları toplam beğeni sayısı üzerinde anlamlı bir etkisi yoktur/vardır.

H5: Markaların paylaşımlarının günün hangi saatinde yapıldığının kullanıcıların paylaşıma yaptıkları toplam beğeni sayısı üzerinde anlamlı bir etkisi yoktur/vardır.

Yukarıda detaylıca anlatılan kavramsal çerçeve aşağıda matematiksel bir model olarak önerilmektedir.

$Y=\beta_{0}+\beta_{1} *$ Video $+\beta_{2} *$ Resim $+\beta_{3} *$ Gif $+\beta_{4} *$ Link $+\beta_{5} *$ Uzunluk0 $-50+\beta_{6} *$ Uzunluk51-100 $+\beta_{7} *$ Uzunluk151 $-200+\boldsymbol{\beta}_{\mathbf{8}} *$ Uzunluk $>200+\sum_{h=0}^{23} \boldsymbol{\beta}_{\mathbf{9}, \boldsymbol{h}} * D h+\sum_{d=1}^{6} \boldsymbol{\beta}_{10, d} * D d+\varepsilon$

Modelde Y ile gösterilen bağımlı değişken olup üç farklı değeri (paylaşım, beğeni veya yorum sayıları) göstermektedir. Burada farklı bağımlı değişkenler için üç farklı matematiksel model ortaya çıkmaktadır. Yukarıda verilen modelde, bağımsız değişkenlerin her birinin beğeni, paylaşım ve yorum üzerindeki etkileri çoklu regresyon metodu ile analiz edilerek, bu değişkenlerin etkisinin bağımlı değişken üzerinde anlamlı olup olmadığı araştırılabilir. Regresyon analizinde çoklu doğrusal bağıntı problemi yaşamamak için matematiksel modelde, 101 ve 150 karakter arasındaki uzunlukta olan paylaşımların, günün saatlerinden bir tanesinin (modelde 23 adet saat bulunmaktadır) ve haftanın günlerinden bir tanesinin (modelde 6 adet haftanın günü bulunmaktadır) model dışında bırakılması gerekmektedir (Büyükuysal ve Öz, 2016).

\section{Modelde kullanılan bağımsız değişkenler}

Video: Markanın paylaşımlarının video içerip içermediği kukla değişken olarak 0 veya 1 olarak kodlanır.

- Resim: Markanın paylaşımlarının resim içerip içermediği kukla değişken olarak 0 veya 1 olarak kodlanır.

- Link: Markanın paylaşımlarının link içerip içermediği kukla değişken olarak 0 veya 1 olarak kodlanır.

- Uzunluk0-50: Markanın paylaşımlarının karakter uzunluğunun 0 ile 50 karakter arasında olup olmadığı kukla değişken olarak 0 veya 1 olarak kodlanır.

- Uzunluk51-100: Markanın paylaşımlarının karakter uzunluğunun 51 ile 100 karakter arasında olup olmadığı kukla değişken olarak 0 veya 1 olarak kodlanır.

- Uzunluk151-200: Markanın paylaşımlarının karakter uzunluğunun 151 ile 200 karakter arasında olup olmadığı kukla değişken olarak 0 veya 1 olarak kodlanır.

- Uzunluk > 200: Markanın paylaşımlarının karakter uzunluğunun 200 karakterden büyük olup olmadığı kukla değişken olarak 0 veya 1 olarak kodlanır.

- Dh: Marka paylaşımlarının günün hangi saatinde yapıldığının 23 farklı saat için kukla değişkenle 0 veya 1 olarak kodlanmasıdır.

- Dd: Marka paylaşımlarının haftanın hangi gününde yapıldığının 6 farklı gün için kukla değişkenle 0 veya 1 olarak kodlanır.

\subsection{Araştırma Tasarımı}

Bu çalışmada önerilen modelin analiz edilebilmesi için Şekil 2'de gösterilen araştırma tasarımı sunulmaktadır. Bu analizin yapılabilmesi için sosyal medyadan veri elde edilmesi gerekmektedir. Bu verinin içeriğinde işletmelerin sosyal medya hesapları üzerinden yapmış oldukları paylaşımların karakteristik özelliklerine ve kullanıcılar üzerindeki etkilerini ölçümlemek üzere de kullanıcıların sosyal medya üzerinden yapmış oldukları beğeni, paylaşım ve yorum sayılarına ihtiyaç bulunmaktadır. Araştırma tasarımının ilk adımında üzerinde araştırma yapılacak sosyal medya ağının seçilmesi ve bu ağ üzerinden paylaşım yapan markaların belirlenmesi gerekmektedir. İkinci adımda sosyal medya verilerine API'lar ile ulaşılır. Daha sonra işletmelerin yapmış oldukları paylaşım içerikleri ve bunlara yapılan paylaşım, beğeni, yorum gibi sayısal veriler toplanır ve veritabanına kaydedilir. En son adımda da verilerin analizi gerçekleştirilir. Sosyal medya sonsuz bir veri kaynağıdır fakat bu veri kaynağından veri seti elde etmek için özel yazılımlar ve uzmanlık gerekmektedir. Bu konuda araştırmacılara ışık tutması amacıyla dünyanın en popüler sosyal medya ağlarından biri olan Twitter'dan verilerin nasıl elde edileceğine dair veri toplama metodu aşağıda detaylıca anlatılmaktadır. 
Şekil 2: Araştırma Tasarımı

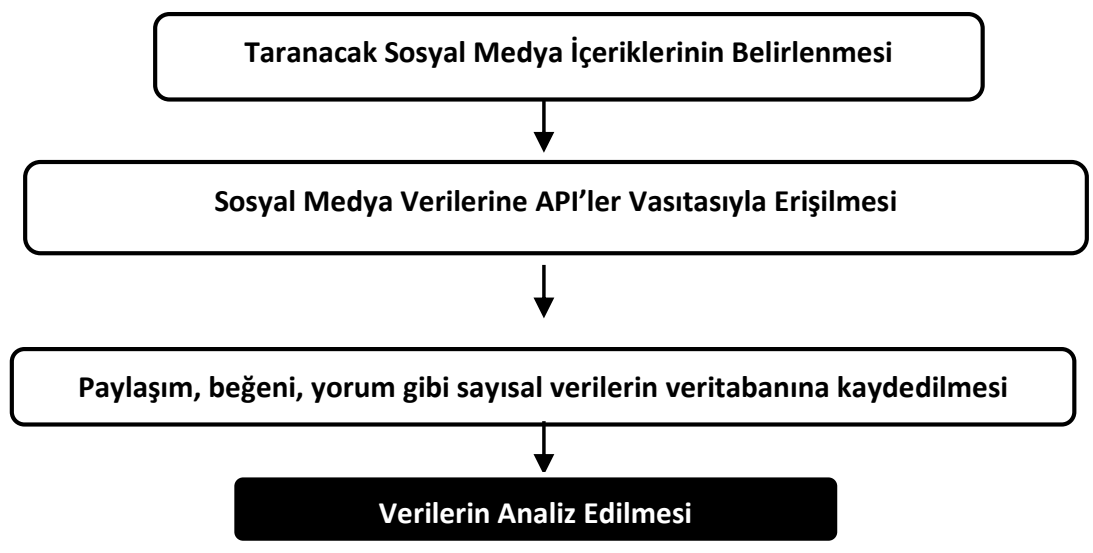

\subsection{Veri Toplama Metodu}

Twitter kısa internet metinlerinin paylaşılması fikri ile ortaya çıkmış bir sosyal mikro blog platformudur. Özellikle 2008 yılında Mısır'da hapsedilen bir Amerikan öğrencinin telefonundan yalnızca "tutuklandım" (arrested) metnini içeren bir tweet atması ve sonrasında serbest bırakılması ile birlikte dünyada popüler olmuştur (Simon, 2008; Kwak vd., 2010). Twitter yapı itibari kullanıcıların birbirlerini kolayca takip edebildikleri, takip ettikleri kişilerin paylaşımlarını akış ekranlarında görebildikleri, başlangıçta 140 karakter olan, daha sonra 280 karaktere çıkarılan ve "tweet" ismi verilen içerikler paylaşmasını sağlamaktadır. Bu paylaşımlar başlangıçta tamamen metin içerirken daha sonra görsel içeriklerin de tweetlerin içinde paylaşılması sağlanmıştır. Hashtag ismi verilen, metinlerin başına diyez (\#) işareti koyarak, bağlantısı sağlanan kelimeler ile bu hashtage sahip diğer tweetlerin gruplanması sağlanmıştır. Böylelikle bir gündem olduğunda kullanılan hashtagler ile lokasyon bazlı olarak haberleşme ve içerik paylaşımı sağlanabilmektedir.

Her gün milyonlarca kişinin kullandığı bu tweetlere erişmek istenildiğinde bir internet servisi olan Twitter API kullanılmaktadır, bu servis Twitter'ın resmi olarak verilerini kamuoyu ile paylaştığı platformudur. Bu servis ile Twitter'ın belirlediği kural ve izinler çerçevesinde kullanıcıların sosyal medya paylaşımlarına erişim sağlanabilmektedir. Bu kurallardan bazıları; saniyede kaç istekte bulunabileceği, kaç günlük veri çekilebileceği, bu verilerin hani kelimeleri içereceği gibidir. Örneğin bu servis ile 15 dakika içinde 1500 adet tweet çekilebilmekte ve geriye dönük olarak yalnızca bir haftalık veriye erişilebilmektedir. Bu da geniş bir veri setine ihtiyaç duyulan çalışmalar için engel teşkil etmektedir. Twitter API servisinin limitleri sebebi ile alternatif bir kaynağa ihtiyaç duyulmuştur. Açık kaynaklı olarak Github'da sunulan GetOldTweets yazılımı ile ihtiyaç duyulan sosyal medya paylaşımlarını elde edecek şekilde geliştirilerek 100 bine yakın tweeet tek seferde çekilebilmektedir. Burada en önemli husus geçmiş tweetleri bir tarih aralığı vererek elde edebilmektir. Böylece markaların geçmiş lansmanları ve bu aralıktaki tüketicilerin attığı tweetler incelenebilir ve bu sayede saniyeler içinde yüzlerce tweet çekilebilir.

Teknik olarak Python'un gelişmiş altyapısı sayesinde Twitter'ın detaylı arama altyapısı kullanılarak, elde edilmek istenilen kelimeyi ve diğer detayları içeren bir istek gönderilir ve sorgunun sonucunda dönen JSON değeri parçalarına ayrılarak, tweetin alt objeleri alınabilir. Uygulamanın web ayağında açık kaynaklı olan PHP programlama dili kullanılabilir. Bu yapının çalışabilmesi için sanal ya da canlı bir sunucu kurularak veritabanı ile bağlantısı kurulmalıdır. Web sunucusunun hedefi excel dosyalarında ayrı ayrı yeralan farklı boyutlardaki verileri toparlayıp veritabanına yazdırmak ve yine bu veritabanına erişip okumaktır. Pyton ile Excel'e kaydedilen dosyalarda özel karakter kodlamalı dillerde sorun yaşanmaktadır. Bununla birlikte Excel'de kayıtlı verilere dışarıdan erişip okumak oldukça zordur. Bu sebeple yapısal bir veritabanı içine aktarılması analiz işlemlerini kolaylaştırmada zaruridir. Bu sebeple önceden bir Mysql veritabanı oluşturularak bu veritabanına Excel dosyalarındaki satırları dönerek atabilmek için Mysql'in LOAD DATA LOCAL INFILE komutu PHP'nin PDO sınıfının "exec" komutu ile çalıştırılmalıdır. Burada özel karakter kodlamalarının aktarılabilmesi için karakter kodlaması olarak utf8mb4 seçilmiştir. Böylelikle elde edilen bu veriler bu veritabanı ile yukarıda önerilen matematiksel modelin analiz edilmesi için kullanılabilir. 


\section{BULGULAR VE TARTIŞMA}

Bu çalışmada günümüzde artık hayatımızın önemli bir parçası olan sosyal medya ve etrafında gelişen pazarlama aktiviteleri analiz edilip, markaların resmi sosyal medya hesaplarından yaptıkları paylaşımların içerik ve özelliklerinin sosyal medya kullanıcıları üzerindeki etkisi araştırılmıştır. Bu çalışmada bahsedilen etkinin belirlenmesi için bir kavramsal çerçeve ve matematiksel model önerilmektedir. Modelde bağımlı değişken olarak paylaşım, beğeni veya yorum sayıları bulunmaktadır. Tablo $1^{\prime}$ de modellerde kullanılan bağımlı ve bağımsız değişkenler özet olarak gösterilmektedir.

Tablo 1: Önerilen Matematiksel Modelin Özeti

\begin{tabular}{|c|c|c|}
\hline $\begin{array}{lcc}\text { 1. } & \text { Model } & \text { Bağımlı } \\
\text { 2. } & \text { Model } & \text { Bağımlı } \\
\text { 3. } & \text { Model } & \text { Bağımlı Değişken: }\end{array}$ & $\begin{array}{l}\text { Değişken: } \\
\text { Değişken: }\end{array}$ & $\begin{array}{r}\text { Beğeni, } \\
\text { Paylaşım, }\end{array}$ \\
\hline \multicolumn{3}{|c|}{ Bütün Modeller İçin Kullanılan Bağımsız Değişkenler } \\
\hline Video & Kukla Değişken & \\
\hline Resim & Kukla Değişken & \\
\hline Gif & Kukla Değişken & \\
\hline Link & Kukla Değişken & \\
\hline Uzunluk (0-50 karakter) & Kukla Değişken & \\
\hline Uzunluk (51-100 karakter) & Kukla Değişken & \\
\hline Uzunluk (151-200 karakter) & Kukla Değişken & \\
\hline Uzunluk (200 karakterden büyük) & Kukla Değişken & \\
\hline 23 Adet Günün Saatleri & 23 Adet Kukla Değişken & \\
\hline 6 Adet Haftanın Günleri & 6 Adet Kukla Değişken & \\
\hline
\end{tabular}

Tabloya göre bahsi geçen üç farklı matematiksel model aynı bağımsız değişkenlerle verilmektedir. Modelde bulunan bağımsız değişkenler belirlenen karakteristik özelliğin paylaşımda bulunup bulunmamasına göre kukla değişken olarak kodlanmıştır. Bağımsız değişken olarak belirtilmiş olan karakteristik özellikler paylaşımda video, resim, gif ve link bulunup bulunmaması, paylaşım uzunluğunun kısa, orta veya uzun olması ve paylaşım zamanıdır.

$\mathrm{Bu}$ araştırmada önerildiği gibi sosyal medya ağlarından veri elde edildiğinde, işletme paylaşımlarının en etkili olan içerik karakteristikleri, sunulan matematiksel modelin analiz edilmesiyle elde edilebilir. Bunun için analiz yöntemi olarak regresyon analizi uygulanabilir. Analiz sonuçlarına göre her bir bağımsız değişkenin bağımlı değişkenler üzerinde anlamlı bir etkisinin bulunup bulunmadığı elde edilir ve buna göre bir paylaşımda video, resim, gif veya link bulunmasının sosyal medya kullanıcıları üzerindeki etkileri niceliksel olarak belirlenebilir. Kullanıcılar üzerindeki etkinin belirlenmesi için bağımlı değişken olarak beğeni, paylaşım ve yorum ele alınmıştır. Modelde $\beta$ ile gösterilen katsayılar her bir paylaşım içeriğinde belirlenen karakteristiğin olmasının sosyal medya kullanıcılarından paylaşıma gelecek tepkiye (beğeni, paylaşım veya yorum olarak) olacak etkisini vermektedir. Ayrıca aynı modelin analiz sonuçlarına göre paylaşım karakter uzunluğunun yine kullanıcılar üzerinde anlamlı pozitif bir etki yaratıp yaratmadığı sonucuna ulaşılabilir.

Markaların paylaşımlarının günün hangi saatinde olduğu, kullanıcılar üzerinde anlamlı bir etkisinin bulunmadığı yine aynı analiz sonuçlarına göre elde edilecektir. Bu nedenle özellikle sosyal medya yöneticilerine bu çalışmada tavsiye edilen kendi takipçilerinin paylaşımlarının analiz edilerek en çok hangi gün ve saatte yaptıkları gönderilere en çok tepkiyi verdiklerini belirleyip ona göre paylaşım ve saatlerinin belirlenmesi olacaktır. Bu modele ek olarak ayrıca markaların görsel marka dili ve marka kimliği açısından ele alınması, bu kavramlarla değerlendirilmesi ve sadık müşterilerin yaklaşımları incelenmesi de önerilmektedir.

\section{SONUÇ}

Markalar daha önce yaptıkları paylaşım içeriklerine verilen tepkiler üzerinde bu çalışmada önerilen matematiksel modeli uygulayarak, gelecekte yapacakları paylaşımların en etkili olabilmesi için nasıl bir karakteristikte olması gerektiğini belirleyebilirler. Böylece yapacakları paylaşımların kullanıcılar üzerindeki etkilerini maksimum düzeye çıkarabilirler. Bu etkilerin farklı zamanlarda farklı olması da beklenen bir sonuçtur. Örneğin bir markanın lansman döneminde yapmış olduğu paylaşımlara verilen kullanıc tepkileri farklı olabilir. Bu nedenle markaların farklı paylaşım dönemleri belirleyip bu araştırmayı farklı zaman dilimleri içinde yapmaları daha doğru ve güvenilir sonuçlar bulmalarını sağlayacaktır. Çalışmada önerilen veri toplama metodu ile farklı sektörden markaların sosyal medya ağlarından yapmış oldukları paylaşımları ile ilgili veri elde edilebilir. Böylece farklı sektördeki işletmelerin sosyal medyada yaptıkları paylaşımların etkileri niceliksel olarak ölçülebilir. Bu etkiler kullanıcıların 
paylaşımlara yaptıkları beğeni, paylaşım ve yorum sayılarıdır. Paylaşım karakteristikleri farklılaştıkça kullanıcıların verdikleri tepkilerin değişmesi beklenmektedir.

Burada önerilen modele ek olarak daha farklı matematiksel modeller geliştirilerek kullanıcı tepkilerinin ölçümlemdiği beğeni, paylaşım ve yorumların etkileşiminin de dikkate alındığı modeller de kullanılabilir. Ayrıca paylaşım karakteristiği olarak farklı etkenler de modele eklenebilir. Örneğin bu karakteristikler paylaşım içeriğinin bilgilendirici olup olmaması, eğlendirici olup olmaması, paylaşım içeriğinde emojilerin bulunup bulunmaması gibi etkenler olabilir. Bu karateristiklerin etkileri de matematiksel modele eklenip ileriki çalışmalar için model daha da genişletilebilir. Bunun için öncelikli olarak üzerinde çalışımak istenen markanın paylaşımları ele alınıp bu karakteristiklerin belirlenmesi ve matematiksel modele eklenmesi gerekmektedir.

Markaların hem hedef kitle hem marka değeri olarak birbirinden farklı olup sosyal medya hesapları üzerinden yaptıkları paylaşımların kullanııılar üzerindeki etkilerinin de farklı olacağı beklenmektedir. Bu nedenle çalışmada önerilen her bir markanın kendi verileri üzerinden paylaşım, içerik ve özelliklerinin kullanıcılar üzerindeki etkilerini araştırmaları ve bu sonuçlar neticesinde kendi sosyal medya paylaşım stratejilerini oluşturmalarıdır. Bu stratejilerin pazarlamada yer bulan marka kimliği ve marka görsel marka diline uygun olarak oluşturmaları gerekmektedir. Böylece markanın müşterilerin zihnindeki yeri bu paylaşımlarla değişmemesi ya da değiştirilmek isteniyorsa da buna uygun marka kimliği oluşturulması gerekmektedir. Marka kimliği marka sadakati için de önemli bir olgudur. Çünkü sadık müşterilerin zihninde belirli bir marka algısı bulunduğu ve bu sadık müşterilerin kaybedilmemesi için bu algıya uygun stratejilerin sosyal medya üzerinden de ulaştırılması çok doğru olacaktır.

\section{KAYNAKLAR}

Akçay, M. A. (2013). Dünya değerler anket verilerinin veri madenciliği yöntemiyle incelenmesi. Yüksek Lisans Tezi, İstanbul Aydın Üniversitesi, Fen Bilimleri Enstitüsü, Bilgisayar Mühendisliği Ana Bilim Dalı, İstanbul, Türkiye, 23-25.

Alpaydın, E. (2000). Zeki veri madenciliği: ham veriden altin bilgiye ulaşma Yöntemleri. Bilişim 2000 Eğitim Semineri, Boğaziçi Üniversitesi, İstanbul.

Bagozzi, R. P., Dholakia, U. M. (2006). Antecedents and purchase consequences of customer participation in small group brand communities. International Journal of research in Marketing, 23(1), 45-61.

Barnaghi, P., Ghaffari, P., Breslin, J. G. (2016). Opinion mining and sentiment polarity on twitter and correlation between events and sentiment. In Big Data Computing Service and Applications (BigDataService), 2016 IEEE Second International Conference on (pp. 52-57). IEEE.

Berger, J., Sorensen, A. T., Rasmussen, S. J. (2010). Positive effects of negative publicity: when negative reviews increase sales. Marketing Science, 29(5), 815-827.

Bayo-Moriones, A., Lera-López, F. (2007). A firm-level analysis of determinants of ICT adoption in Spain. Technovation, 27(6-7), 352-366.

Berthon, P. R., Pitt, L. F., Plangger, K., Shapiro, D. (2012). Marketing meets Web 2.0, social media, and creative consumers: implications for international marketing strategy. Business horizons, 55(3), 261-271.

Blossom, J. (2009). Content nation-surviving and thriving as social media changes our work, our lives and our future. India: Wiley Publishing Inc, 1. Baskı.

Borgatti, S., Foster, P. (2003). The network paradigm in organizational research: a review and typology. Journal of Management, 29(6), 9911013.

Brookes, E. J. (2010). The anatomy of a Facebook post: study on post performance by type, day of the week, and time of day. Vitrue Inc.

Brunner, R., Emery, S., Hall, R. (2008). Do you matter?: how great design will make people love your company. FT Press.

Budden, C. B., Anthony, J. F., Budden, M. C., Jones, M. A. (2011). Managing the evolution of a revolution: marketing implications of internet media usage among college students. College Teaching Methods and Styles Journal, 3 (3), 5-10.

Büyükuysal, M. Ç., Öz, İ. İ. (2016). Çoklu doğrusal bağinti varliğinda en küçük karelere alternatif yaklaşim: Ridge Regresyon. Düzce Üniversitesi Sağlık Bilimleri Enstitüsü Dergisi, 6(2), 110-114.

Chevalier, J. A., Mayzlin, D. (2006). The effect of word of mouth on sales: online book reviews. Journal of marketing research, 43(3), 345-354.

De Vries, L., Gensler, S., Leeflang, P. S. (2012). Popularity of brand posts on brand fan pages: an investigation of the effects of social media marketing. Journal of interactive marketing, 26(2), 83-91.

Dellarocas, C., Wood, C. A. (2008). The sound of silence in online feedback: estimating trading risks in the presence of reporting bias. Management science, 54(3), 460-476. 
Dholakia, U. M., Bagozzi, R. P., Pearo, L. K. (2004). A social influence model of consumer participation in network-and small-group-based virtual communities. International journal of research in marketing, 21(3), 241-263.

Dholakia, U. M., Durham, E. (2010). One café chain's Facebook experiment. Harvard Business Review, 88(3), 26.

Dick, A. S., Basu, K. (1994). Customer loyalty: toward an integrated conceptual framework. Journal of the academy of marketing science, 22(2), 99-113.

Dunbar, R. I. M. (1992). Neocortex size as a constraint on group size in primates. Journal of Human Evolution, 22(6), 469-493.

Eley, B., Tilley, S. (2009). The art \& science of online marketing. Australia, SitePoint.

Engeström, J. (2005). Why some social network services work and others don't -- Or: the case for object-centered sociality. Erişim http://www. zengestrom.com/blog/2005/04/why-some-social-network-services-work-and-others-dont-or-the-case-for-object-centered-sociality.html

Frawley, W. J., Piatetsky-Shapiro, G., Matheus, C. J. (1992). Knowledge discovery in databases: an overview. Al magazine, $13(3)$, 57.

Gillin, P. (2010). The new conversation: taking social media from talk to action. Harvard Business Review, 1-24.

Goldenberg, J., Libai, B., Moldovan, S., Muller, E. (2007). The NPV of bad news. International Journal of Research in Marketing, 24(3), $186-200$.

Gommans, M., Krishman, K. S., Scheffold, K. B. (2001). From brand loyalty to e-loyalty: a conceptual framework. Journal of Economic \& Social Research, 3(1).

Grau, J. (2009). US retail e-commerce: slower but still steady growth. Emarketer, Retrieved April, 5.

He, W., Zha, S., Li, L. (2013). Social media competitive analysis and text mining: a case study in the pizza industry. International Journal of Information Management, 33(3), 464-472.

Hennig-Thurau, T., Gwinner, K. P., Walsh, G., Gremler, D. D. (2004). Electronic word-of-mouth via consumer-opinion platforms: what motivates consumers to articulate themselves on the Internet?. Journal of interactive marketing, 18(1), 38-52.

Ho-Dac, N. N., Carson, S. J., Moore, W. L. (2013). The effects of positive and negative online customer reviews: do brand strength and category maturity matter?. Journal of Marketing, 77(6), 37-53.

Huberman, B. A., Romero, D. M., Wu, F. (2008). Social networks that matter: Twitter under the microscope. arXiv preprint arXiv:0812.1045.

Ibrahim, N. F., Wang, X., Bourne, H. (2017). Exploring the effect of user engagement in online brand communities: evidence from Twitter. Computers in Human Behavior, 72, 321-338.

Kaplan, A. M., Haenlein, M. (2010). Users of the world, unite! The challenges and opportunities of social media. Business Horizons, 53 (1), $59-68$.

Keath, J., Kistner, J., Mirman, E., Levey, J. (2011). Facebook page marketing. HubSpot Retrived, 24-2.

Kierzkowski, A., Mcquade, S., Waitman, R., Zeisser, M. (1996). Current research: marketing to the digital consumer. The mckinsey quarterly, (2), 180-183.

Kietzmann, J. H., Hermkens, K., McCarthy, I. P., Silvestre, B. S. (2011). Social media? Get serious! Understanding the functional building blocks of social media. Business Horizons, 54(3), 241-250.

Kim, E., Sung, Y., Kang, H. (2014). Brand followers' retweeting behavior on Twitter: how brand relationships influence brand electronic word-ofmouth. Computers in Human Behavior, 37, 18-25.

Kiygi-Calli, M., Weverbergh, M., Franses, P. H. (2012). The effectiveness of high-frequency direct-response commercials. International Journal of Research in Marketing, 29(1), 98-109.

Kotler, P., Armstrong, G. (2012). Principles of marketing. Pearson education.

Kozinets, R. V. (1999). E-tribalized marketing?: the strategic implications of virtual communities of consumption. European Management Journal, 17(3), 252-264.

Kozinets, R. V., De Valck, K., Wojnicki, A. C., Wilner, S. J. (2010). Networked narratives: understanding word-of-mouth marketing in online communities. Journal of marketing, 74(2), 71-89.

Kumar R., Novak J., Tomkins A. (2010). Structure and evolution of online social networks. Link mining: Models, algorithms, and applications, Springer, New York, 337-357.

Kwak, H., Lee, C., Park, H., Moon, S. (2010, April). What is Twitter, a social network or a news media?. In Proceedings of the 19th international conference on World wide web (pp. 591-600). AcM.

Little, J. D. (1979). Aggregate advertising models: the state of the art. Operations research, 27(4), 629-667.

Lockwood, T., Walton, T. (2008). Building design strategy. Using Design to Achieve Key Business. 
Mangold, W. G., Faulds D. J. (2009). Social media: the new hybrid element of the promotion mixed. Bussines Horizons. 52, $357-365$.

Marchand, A., Hennig-Thurau, T., Wiertz, C. (2017). Not all digital word of mouth is created equal: understanding the respective impact of consumer reviews and microblogs on new product success. International Journal of Research in Marketing, 34(2), 336-354.

McAlexander, J. H., Schouten, J. W., Koenig, H. F. (2002). Building brand community. Journal of marketing, 66(1), 38-54.

Misner, I. R., Devine, V. (1999). The world's best-known marketing secret: building your business with word-of-mouth marketing. Austin, TX: Bard Press.

Moralığlu, D. (2014). Ben marka olsam. Epsilon Yayınları, İstanbul.

Muñiz, A. M., O'guinn, T. C. (2001). Brand community. Journal of consumer research, 27(4), 412-432.

Nail, J. (2005). What's the buzz on word-of-mouth marketing? Social computing and consumer control put momentum into viral marketing. Forrester Research.

Nam, H., Joshi, Y. V., Kannan, P. K. (2017). Harvesting brand information from social tags. Journal of Marketing, 81(4), 88-108.

Nielsen. (2016). Connected Commerce Is Creating Buyers Without Borders, Nielsen http://www.nielsen.com/us/en/insights/news/2016/connected-commerce-is-creating-buyers-without-borders.html.

Özkan, Y. (2008). Veri madenciliği yöntemleri. Papatya Yayıncılık, İstanbul.

Pauwels, K., Aksehirli, Z., Lackman, A. (2016). Like the ad or the brand? Marketing stimulates different electronic word-of-mouth content to drive online and offline performance. International Journal of Research in Marketing, 33(3), 639-655.

Roshanaei, M., Mishra, S. (2015). Studying the attributes of users in Twitter considering their emotional states. Social Network Analysis and Mining, 5(1), 34.

Ryan, D., Jones, C. (2009). Understanding digital marketing. Philadelphia, PA: Kogan Page Limited.

Ryan, K. S., Zabin, J. (2010). Gleansight: social media marketing. Gleanster LCC, 1-21.

Safko, L. (2010). The social media bible: tactics, tools, and strategies for business success. John Wiley \& Sons. New Jersey, 3. Baskı, 3.

Shankar, V., Batra, R. (2009). The growing influence of online marketing communications.

Sharp, B., Sharp, A. (1997). Loyalty programs and their impact on repeat-purchase loyalty patterns. International journal of Research in Marketing, 14(5), 473-486.

Simon, M. (2008). Student 'Twitters' his way out of Egyptian jail. Erişim: http://edition.cnn.com/2008/TECH/04/25/twitter.buck/.

Silva, J. M., Mahfujur Rahman, A. S. M., El Saddik, A. (2008, October). Web 3.0: a vision for bridging the gap between real and virtual. In Proceedings of the 1st ACM international workshop on Communicability design and evaluation in cultural and ecological multimedia system (pp. 9-14). ACM.

Smith, A. N., Fischer, E., Yongjian, C. (2012). How does brand-related user-generated content differ across YouTube, Facebook, and Twitter?. Journal of interactive marketing, 26(2), 102-113.

Statistica. (2018). Nokia's net sales from 1999 to 2017 (in billion euros). Erişim: https://www.statista.com/statistics/267819/nokias-net-salessince-1999.

Tiago, M. T. P. M. B., Veríssimo, J. M. C. (2014). Digital marketing and social media: why bother?. Business Horizons, 57(6), 703-708.

Truong, Y., Klink, R. R., Simmons, G., Grinstein, A., Palmer, M. (2017). Branding strategies for high-technology products: the effects of consumer and product innovativeness. Journal of Business Research, 70, 85-91.

Trusov, M., Bucklin, R. E., Pauwels, K. (2009). Effects of word-of-mouth versus traditional marketing: findings from an internet social networking site. Journal of marketing, 73(5), 90-102.

We Are Social. (2018). Global Digital Report 2018. Erişim: https://wearesocial.com/blog/2018/01/global-digital-report-2018.

Webber, T. (2010). Why companies watch your every Facebook, YouTube, Twitter move. Erişim: https://www.bbc.com/news/business11450923.

Wilson, A. E., Giebelhausen, M. D., Brady, M. K. (2017). Negative word of mouth can be a positive for consumers connected to the brand. Journal of the Academy of Marketing Science, 45(4), 534-547.

Zhou, W., Duan, W. (2015). An empirical study of how third-party websites influence the feedback mechanism between online word-of-mouth and retail sales. Decision Support Systems, 76, 14-23. 